RONDON, E.S. et al. Miosite dos músculos mastigatórios em Rottweiler - Relato de caso.

PUBVET, Londrina, V. 5, N. 22, Ed. 169, Art. 1141, 2011.

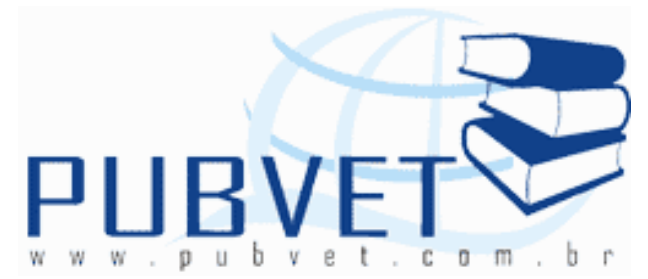

PUBVET, Publicações em Medicina Veterinária e Zootecnia.

\title{
Miosite dos músculos mastigatórios em Rottweiler - Relato de caso
}

Eric Schmidt Rondon ${ }^{1 *}$, Tatiana Rodrigues Dutra ${ }^{2}$, Sabrina Martins Ferreira ${ }^{3}$, Luciana Gonçalves Pinto ${ }^{4}$

${ }^{1}$ MV, MSc, PhD - Professor Adjunto - DMV, FAMEZ, UFMS.

${ }^{2}$ MV, MSC - SMSDC - Prefeitura do Rio de Janeiro.

${ }^{3}$ MV - Clínica Médica - CETRA-RJ.

${ }^{4}$ MV, MSc - Médica Veterinária autônoma.

* Autor para correspondência. E-mail: itacron@gmail.com

\section{Resumo}

A apresentação clínica da miosite dos músculos mastigatórios (MMM) em cães reflete a miopatia focal inflamatória dos músculos da mastigação enquanto a musculatura dos membros locomotores não é afetada. Os sinais se estendem da tumefação aguda dos músculos temporais e masseteres, restrição no movimento da mandíbula, dor na mandíbula e exoftalmia até a atrofia muscular. O diagnóstico é confirmado pela coleta de tecido para biópsia. 0 diagnóstico precoce e a terapia com doses imunossupressoras de corticosteroides normalmente conduzem a um prognóstico bom. Este trabalho relata um caso de MMM em um Rottweiler.

Palavras-chave: atrófica, cão, mastigatória, miosite. 
RONDON, E.S. et al. Miosite dos músculos mastigatórios em Rottweiler - Relato de caso.

PUBVET, Londrina, V. 5, N. 22, Ed. 169, Art. 1141, 2011.

\section{Masticatory muscle myositis in Rottweiler - Case report}

\section{Abstract}

The clinical presentation of masticatory muscle myositis (MMM) in dogs reflects focal inflammatory myopathy of the muscles of mastication, while limb muscles are spared. Signs range from acute swelling of the temporalis and masseter muscles, restricted jaw movement, jaw pain, and exophthalmus, to muscle atrophy. The diagnosis is confirmed by a muscle biopsy. Early diagnosis and therapy with immunosuppressive doses of corticosteroids usually yields a good prognosis. This paper reports a case of MMM in a Rottweiler.

Keywords: atrophic, dog, masticatory, myositis.

\section{1 - INTRODUÇÃO}

A miosite dos músculos mastigatórios (MMM) é uma afecção inflamatória envolvendo os músculos da mastigação (masseter, temporal e pterigoide) no cão (Kahn, 2001; Barton, et al., 2004).

A doença tem etiologia desconhecida (Nelson, et al., 2001). Entretanto, está relacionada à resposta imunomediada (Blot, 2004) contra as fibras musculares $2 \mathrm{M}$ constituídas pelas miosinas chamadas de mastigatórias, por terem origem embriológica distinta das demais (Hoh, 2002). Recentemente, foi identificada a proteína de ligação C da miosina mastigatória (mMyBPC, "masticatory myosin binding protein-C") localizada não somente no interior, como também na superfície das células dos músculos mastigatórios o que a torna mais acessível como imunógeno (Wu, et al., 2007).

A MMM pode ocorrer em qualquer raça de cães, mas Rottweilers, Samoiedas, Dobermanns Pinschers, Retrievers (Taylor, 2000) e Pastores Alemães (Blot, 2004) são especialmente afetadas. Os cães jovens e de meia idade são primariamente acometidos, com a média etária de três anos para o início dos sinais. Não há predileção sexual aparente (Taylor, 2000).

Foram descritos, inicialmente, dois distúrbios separados: miosite eosinofílica e miosite atrófica. Contudo, considera-se provável que 
RONDON, E.S. et al. Miosite dos músculos mastigatórios em Rottweiler - Relato de caso. PUBVET, Londrina, V. 5, N. 22, Ed. 169, Art. 1141, 2011.

correspondam, respectivamente, aos estádios agudo e crônico da MMM (Anderson, et al., 1993).

O sinal clássico da MMM é a incapacidade de abertura da mandíbula, mesmo sob anestesia geral (University of California, 1999). A relutância do paciente em se alimentar acompanhada por salivação intensa é também um achado frequente (Taylor, 2000).

A forma aguda da MMM caracteriza-se por hipertrofia dos músculos temporal e masseter acompanhada por mialgia. Ocasionalmente, pode ocorrer exoftalmia (Dewey, 2005) levando à neurite óptica e a distúrbios visuais (Vite, 2005). Podem ocorrer febre, adenite local e tonsilite. Porém, na maioria dos casos, a doença se cronifica gerando atrofia muscular progressiva e fibrose que impossibilita a abertura da boca (Blot, 2004) e acarreta a aparência esqueletiforme da cabeça (Quiroz-Rothe, et al., 2002; Nelson, et al., 2001).

A suspeita diagnóstica de MMM é baseada nos sinais clínicos. Nos casos agudos, outras desordens traumáticas, inflamatórias e neoplásicas afetando dentes, olhos, boca e articulações temporomandibulares precisam ser consideradas (University of California, 1999). A MMM crônica deve ser diferenciada da atrofia dos músculos mastigatórios devido à polimiosite ou a lesão do nervo trigêmeo. Cães com atrofia neurológica apresentam mobilidade normal da mandíbula, ao contrário da restrição esperada na MMM. Ademais, a polimiosite provoca atrofia dos músculos da mastigação, mas afeta também a musculatura de todo o corpo (Taylor, 2000).

O diagnóstico de MMM é confirmado através de biópsia muscular, geralmente do músculo temporal (Kahn, 2001; Quiroz-Rothe, et al., 2002), revelando necrose e fagocitose de fibras musculares do tipo $2 \mathrm{M}$ e intenso infiltrado perivascular de linfócitos e plasmócitos. Os histiócitos, eosinófilos e neutrófilos estão presentes em pequeno número. Em cães com MMM crônica predominam a atrofia muscular e a fibrose (Taylor, 2000).

A concentração sanguínea de creatinina-quinase (CQ), aspartatoaminotransferase (AST), lactato desidrogenase (LDH) e aldolase pode estar aumentada, particularmente na MMM aguda (Clemmons, 2002). A anemia 
RONDON, E.S. et al. Miosite dos músculos mastigatórios em Rottweiler - Relato de caso. PUBVET, Londrina, V. 5, N. 22, Ed. 169, Art. 1141, 2011.

moderada, a neutrofilia e a eosinofilia são ocasionalmente identificados. Proteinúria tem sido notada em alguns casos (Taylor, 2000).

$\mathrm{O}$ teste imunocitoquímico demonstra imunocomplexos contra fibras $2 \mathrm{M}$ em mais de $85 \%$ dos casos (Barton, et al., 2004) e anticorpos circulantes são passíveis de deteç̧ão sorológica em $81 \%$ dos cães com MMM. Neste caso, o soro deve ser colhido antes de iniciada a terapia com corticosteroide evitandose um resultado falso negativo decorrente do tratamento (University of California, 1999).

A eletromiografia (EMG) pode auxiliar na confirmação de que a lesão muscular é restrita aos músculos da mastigação além de facilitar na escolha dos locais para a coleta de tecido para a biópsia (Nelson, et al., 2001).

O tratamento é realizado através da administração de doses imunossupressoras de corticosteroides como a prednisona, por via oral (VO), na dose de 1 a $2 \mathrm{mg} / \mathrm{kg}$, a cada 12 ou 24 horas de intervalo (q12-24h). Depois de alcançada a melhora clínica, inicia-se a administração de doses remissivas para a retirada da corticoterapia. Entretanto, a menor dose é mantida em dias alternados por pelo menos seis meses (Vite, 2005).

A dosagem inadequada ou o tempo insuficiente de tratamento estão associados com uma elevada taxa de recorrência (Taylor, 2000). Cães que não respondem adequadamente à corticoterapia ou aqueles que apresentam recidivas quando a dose é reduzida, podem se beneficiar da administração de outras drogas imunossupressoras como a azatioprina ( $2 \mathrm{mg} / \mathrm{kg} / \mathrm{q} 24-48 \mathrm{~h}$, VO) (Carpenter, et al., 1989).

Anteriormente, recomendava-se que cães com miosite atrófica crônica fossem anestesiados e tivessem a abertura da mandíbula forçada. Atualmente esta prática é contra indicada por não promover melhora clínica, por aumentar a inflamação com o traumatismo do músculo e por poder provocar fratura ou luxação mandibular (Barton, et al., 2004).

Sem o reconhecimento precoce e o tratamento agressivo, a perda de miofibras e a fibrose muscular resultam em disfunção irreversível da mandíbula 
RONDON, E.S. et al. Miosite dos músculos mastigatórios em Rottweiler - Relato de caso.

PUBVET, Londrina, V. 5, N. 22, Ed. 169, Art. 1141, 2011.

e atrofia muscular (Barton, et al., 2004). A farmacoterapia torna-se, assim, ineficaz (Blot, 2004).

\section{2 - MATERIAL E MÉTODOS}

\section{Anamnese}

No Hospital Veterinário de Pequenos Animais da Universidade Estácio de Sá na cidade do Rio de Janeiro (CERA/UNESA-RJ), foi recebido para consulta um canino macho, da raça Rottweiler, de oito anos de idade, pesando $38 \mathrm{Kg}$. A queixa principal do proprietário foi que o animal não tinha apetite há três dias.

\section{Exame físico}

Ao exame físico, o animal apresentava-se normocorado e normohidratado. Outros parâmetros vitais (temperatura, frequências cardíaca e respiratória e pulso) estavam dentro da normalidade para a espécie canina, assim como a palpação abdominal e de linfonodos. Havia sialorréia.

O oferecimento de ração na forma líquida demonstrou a presença de apetite e dificuldade na apreensão do alimento (fig.1).

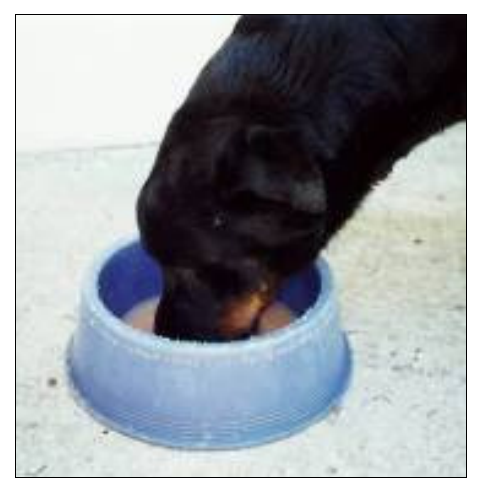

Figura 1: o animal procurava o alimento e sugava-o do comedouro tornando nítida a dificuldade de apreensão. Cão, Rottweiler, macho, 8 anos. 
RONDON, E.S. et al. Miosite dos músculos mastigatórios em Rottweiler - Relato de caso. PUBVET, Londrina, V. 5, N. 22, Ed. 169, Art. 1141, 2011.

Foi constatada severa atrofia dos músculos da face (fig.2), paralisia da articulação temporomandibular que impedia a abertura, ainda que parcial, da boca (fig.3) e otite bilateral por otocaríase.

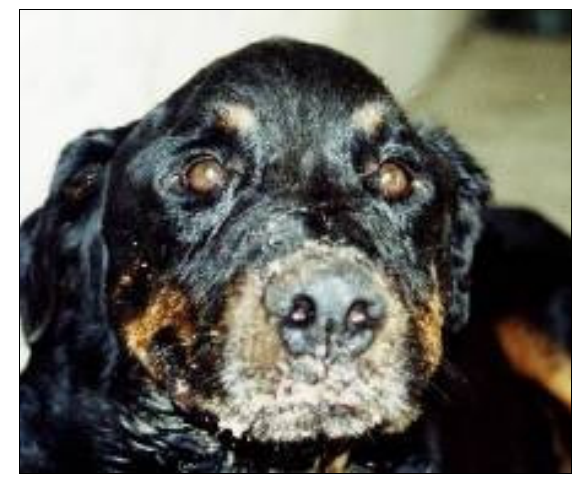

Figura 2: atrofia bilateral simétrica da musculatura temporal dando aparência esqueletiforme à cabeça. Cão, Rottweiler, macho, 8 anos.

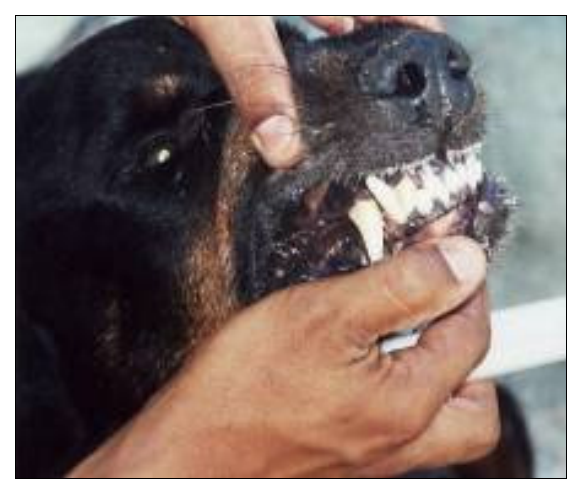

Figura 3: incapacidade para abrir a boca. Cão, Rottweiler, macho, 8 anos.

Optou-se por submeter o animal à anestesia geral intravenosa (Propofol ${ }^{1}, 5 \mathrm{mg} / \mathrm{kg}$ ) para avaliação da amplitude de movimento da articulação temporomandibular e realização de radiografias do crânio. Constatou-se que mesmo em plano anestésico cirúrgico (Guedel, 1951) não era possível abrir a boca do animal.

\footnotetext{
${ }^{1}$ Propofol, Cristália Produtos Químicos e Farmacêuticos Ltda., Itapira - SP.
} 
RONDON, E.S. et al. Miosite dos músculos mastigatórios em Rottweiler - Relato de caso. PUBVET, Londrina, V. 5, N. 22, Ed. 169, Art. 1141, 2011.

\section{Exames complementares}

Os exames complementares realizados foram o hemograma, bioquímica sérica ( $A L T, C Q, L D H)$, urinálise, parasitológico de fezes e coleta de fragmentos dos músculos temporal e masseter para biópsia. Também foi realizada radiografia do crânio com o animal sob anestesia geral.

\section{Tratamento}

A terapia instituída foi prednisolona em dose imunossupressora (2 $\mathrm{mg} / \mathrm{kg} / \mathrm{q} 24 \mathrm{~h}, \mathrm{VO}$ ) e enrofloxacina ${ }^{2}$ ( $5 \mathrm{mg} / \mathrm{kg} / \mathrm{q} 24 \mathrm{~h}, \mathrm{IM}$ ). O animal permaneceu sistemicamente normal, ativo e com apetite preservado. Era alimentado com ração pastosa, diluída em água. Houve a melhora do quadro clínico após a primeira semana de farmacoterapia, notada pela abertura parcial da boca. Entretanto, duas semanas depois, o proprietário decidiu sacrificar o animal sem consultar a equipe do CERA/UNESA.

\section{3 - RESULTADOS E DISCUSSÃO}

A miosite dos músculos mastigatórios (MMM) é uma afecção inflamatória que afeta exclusivamente os músculos da mastigação no cão (Shelton, 2003). A doença pode ocorrer em qualquer raça, mas é mais frequente nas de porte grande, como Rottweilers (Taylor, 2000). Os sinais clínicos costumam aparecer em cães jovens e de meia idade (Quiroz-Rothe, et al., 2002; Taylor, 2000). Neste relato, o paciente era da raça Rottweiler e apresentava 8 anos de idade, fato coincidente com o descrito na literatura.

A incapacidade de abrir a boca é um achado importante para a suspeição de MMM (Blot, 2004) e mesmo sob anestesia geral, não é possível promover esta abertura (University of California, 1999) fato observado pela equipe que atendeu ao caso. Neste aspecto, a realização de anestesia geral foi bastante

2 Flotril 2,5\%, Intervet/Schering-Plough Animal Health, Cruzeiro - SP. 
RONDON, E.S. et al. Miosite dos músculos mastigatórios em Rottweiler - Relato de caso. PUBVET, Londrina, V. 5, N. 22, Ed. 169, Art. 1141, 2011.

útil por permitir a complementação do exame físico, a realização de radiografias e a coleta de fragmentos teciduais.

Existem duas formas da doença - aguda e crônica - diferenciáveis pelos sinais clínicos e pelo exame histopatológico (Quiroz-Rothe, et al., 2002). Curiosamente, em oposição ao relato do proprietário que sugeria a fase aguda da doença, ao exame físico, o paciente apresentava uma severa atrofia da face causando-Ihe aspecto esqueletiforme. Conforme Gilmour, et al.(1992) a fase aguda tem duração de duas a três semanas sendo caracterizada por dor e edema recidivante nos músculos da mastigação. Lewis (1994) citou que, às vezes, esta fase passa despercebida pelo proprietário que encaminha o animal para atendimento médico-veterinário já com a cronificação do processo, na qual ocorre a atrofia muscular da face, geralmente bilateral e simétrica. De fato, em oposição aos dados anamnéticos e em conformidade com a literatura, o animal encontrava-se na fase crônica da doença. Apesar disto, estava ativo, com os parâmetros vitais dentro da normalidade para a espécie e mantinha o apetite.

Os exames laboratoriais geralmente revelam anemia moderada, neutrofilia e eosinofilia. A concentração sanguínea de creatinina-quinase (CQ), aspartato-aminotransferase (AST) e de globulinas pode estar aumentada, particularmente na MMM aguda. Proteinúria tem sido notada em alguns relatos (Nelson, et al., 2001; Taylor, 2000). No caso aqui apresentado, nos exames complementares foram observados basofilia, eosinofilia, neutrofilia e trombocitopenia ao hemograma. A bioquímica sérica não mostrou alterações, provavelmente pela cronificação da doença. A urinálise revelou piúria, hematúria, bacteriúria, presença intensa de debris celulares e cristais em formação achados considerados intercorrentes visto que não há descrição, até o momento, na literatura de uma correlação direta entre MMM e estas alterações.

A radiografia do crânio não revelou anormalidades, e mesmo sob anestesia geral não foi possível abrir a boca do animal. 
RONDON, E.S. et al. Miosite dos músculos mastigatórios em Rottweiler - Relato de caso. PUBVET, Londrina, V. 5, N. 22, Ed. 169, Art. 1141, 2011.

O teste imunocitoquímico, a EMG e a detecção dos anticorpos contra as fibras $2 \mathrm{M}$ no soro não foram realizados por serem meios de diagnóstico menos acessíveis.

Suspeita-se de MMM com base nos sinais clínicos e exame físico (University of California, 1999; Blot, 2004; Anderson, et al., 1993; Nelson, et al., 2001). O diagnóstico pode ser confirmado a partir da coleta de fragmentos teciduais para biópsia, geralmente do músculo temporal (Kahn, 2001) e/ou do masseter (Costa, et al., 2005).

No caso aqui descrito, o paciente teve a suspeita de MMM confirmada através da biópsia. Os cortes histológicos evidenciaram necrose e atrofia de fibras musculares entremeadas por infiltração inflamatória mononuclear, predominantemente linfoplasmocitária. Observou-se tumefação e degeneração de alguns miócitos e necrose individual de fibras. Proliferação de fibroblastos e depósito de colágeno. Ao conjunto de achados concluiu-se por miosite dos músculos mastigatórios.

O tratamento da MMM é realizado através da administração de doses imunossupressoras de corticosteróides (prednisolona, 1-2 mg/kg/q12-24h, VO). A terapia instituída neste caso foi a prednisolona ( $2 \mathrm{mg} / \mathrm{kg} / \mathrm{q} 24 \mathrm{~h}, \mathrm{VO}$ ). Foi prescrito antibioticoterapia com Enrofloxacina ( $5 \mathrm{mg} / \mathrm{kg}$, IM) para o tratamento da infecção urinária.

Houve somente uma melhora parcial do quadro clínico na primeira semana de tratamento, com ligeiro aumento na amplitude do movimento da mandíbula. Nas duas semanas subsequentes o quadro se manteve estável. Segundo Barton, et al. (2004) o reconhecimento precoce e o tratamento agressivo são importantes para o sucesso do tratamento visto que a perda de miofibras e a fibrose muscular resultam em disfunção irreversível do movimento mandibular e atrofia muscular. Fato observado neste caso no qual atribuiu-se a melhora apenas parcial à severa atrofia já instalada. 
RONDON, E.S. et al. Miosite dos músculos mastigatórios em Rottweiler - Relato de caso. PUBVET, Londrina, V. 5, N. 22, Ed. 169, Art. 1141, 2011.

\section{4 - CONCLUSÕES}

A avalição do paciente, sob anestesia geral, é útil na suspeição de MMM. A recuperação do paciente está intimamente relacionada com o diagnóstico precoce da doença e a instituição da terapia imunossupressora.

\section{5 - REFERÊNCIAS BIBLIOGRÁFICAS ${ }^{3}$}

Anderson, Jamie G e Harvey, Colin E. 1993. Masticatory muscle myositis. Journal of Veterinary Dendistry. March de 1993, Vol. 10, 1, pp. 6-8.

Barton, Claudia, et al. 2004. Masticatory muscle myositis: pathogenesis, diagnosis, and treatment. August de 2004, Vol. 26, 8, pp. 590-604.

Blot, Stephane. 2004. Distúrbios dos músculos esqueléticos. [A. do livro] Stephen J Ettinger e Edward C Feldman. Tratato de Medicina Interna Veterinária. Rio de Janeiro : Guanabara Koogan, 2004, pp. 721-729.

Carpenter, J L, et al. 1989. Canine bilateral extraocular polymyositis. Veterinary pathology. November de 1989, Vol. 26, 6, pp. 510-512.

Clemmons, R M. 2002. Peripheral nerve diseases. The Neurology Service at the VMTH. [Online] University of Florida's Veterinary Medical Teaching Hospital, 2002. [Citado em: 17 de Fevereiro de 2011.] http://neuro.vetmed.ufl.edu/neuro/P_Nerves/P_nerv.htm.

Costa, Paulo Renato S, Conceição, Lissandro G e Parzanini, Gyanini R. 2005. Miosite mastigatória em cão: relato de caso. Clínica Veterinária. 2005, 56, pp. 42-46.

Dewey, C w. 2005. Disorders of the peripheral nervous system. [Online] 2005. [Citado em: 19 de Fevereiro de 2011.]

http://www.ivis.org/proceedings/scivac/2005/Dewey5_en.pdf?LA=1in.

Gilmour, A M, Morgan, R V e Moore, F M. 1992. Masticatory myopathy in the dog: a retrospective study of 18 cases. Journal of the American Hospital Association. 1992, Vol. 28, 4, pp. 300-306.

Hoh, Joseph F. Y. 2002. 'Superfast' or masticatory myosin and the evolution of jaw-closing muscles of vertebrates. The Journal of Experimental Biology. 2002, Vol. 205, pp. 2203-2210.

Kahn, Cyntia M. 2001. Manual Merck de Veterinária. São Paulo : Roca, 2001.

Lewis, R M. 1994. Immune-mediated muscule disease. Veterinary Clinics of North America: small animal practice. 1994, Vol. 24, 1, pp. 703-710.

Nelson, Richard $\mathbf{W}$ e Couto, C. Guilhermo. 2001. Medicina Interna de Pequenos Animais. 2. Rio de Janeiro : Guanabara Koogan, 2001. pp. 322-331.

Quiroz-Rothe, E, et al. 2002. Canine atrophic masticatory muscle: a case report. European Journal of Companion Animal Practice. October de 2002, Vol. 12, 2.

Shelton, G Diane. 2003. Distúrbios musculares e de junção muscular. [A. do livro] Stephen ] Bichard e Robert G Sherding. Manual Saunders Clínica de Pequenos Animais. 2. São Paulo : Roca, 2003, pp. 1430-1438.

\footnotetext{
${ }^{3}$ Conforme a norma ISO 690.
} 
Taylor, S M. 2000. Selected disorders of muscle and the neuromuscular junction. Veterinary Clinics of North America: small animal practice. 2000, Vol. 30, 1, pp. 59-62.

University of California. 1999. Comparative Neuromuscular Laboratory. [Online] may de 1999. [Citado em: 17 de fevereiro de 2011.]

http://vetneuromuscular.ucsd.edu/cases/1999/may99.html.

Vite, C H. 2005. Myopathic disorders. Braund's Clinical Neurology in Small Animals:

Localization, Diagnosis and Treatment. Ithaca : International Veterinary Information Service, 2005. Disponível em: http://www.ivis.org/home.asp.

Wu, Xiaohua, et al. 2007. Autoantibodies in canine masticatory muscle myositis: recognize a novel myosin binding Protein-C family member. The Journal of Immunology. 2007, Vol. 179, pp. 4939-4944. 